\title{
THE EFFECT OF CIS- AND TRANS-CLOMIPHENE CITRATE ON SIALIC ACID IN THE UTERUS, CERVIX AND VAGINA OF RATS DURING DELAYED IMPLANTATION
}

\author{
M. S. SANKARAN AND M. R. N. PRASAD \\ Department of Zoology, University of Delhi, Delhi 7, India
}

(Received 20th July 1972)

\begin{abstract}
Summary. The comparative effects of cis- and trans-clomiphene and oestradiol-17 $\beta$ on the sialic acid concentration in the uterus, cervix and vagina were studied in rats during experimentally induced delayed implantation. The cis- or trans-isomer of clomiphene caused a progressive dose-dependent increase in sialic acid in the uterus and cervix whereas vaginal sialic acid decreased with increase in the dose of the respective compounds.

Cis- and trans-clomiphene and oestradiol-17 $\beta$ all caused a sharp increase in the sialic acid content of the uterus, cervix and vagina $6 \mathrm{hr}$ after the administration of the respective compounds. There was a decrease in sialic acid in all the three tissues at subsequent time intervals in cis-clomiphene or oestradiol-treated rats. The oestrogenic effects of trans-clomiphene lasted even up to $48 \mathrm{hr}$ in all three reproductive tract tissues, indicating that trans-clomiphene is more oestrogenic than the cis-isomer. Differences in the response of the uterus, cervix and vagina to administration of the compounds are discussed in relation to their embryological origin.
\end{abstract}

\section{INTRODUCTION}

Sialic acids (acetylated derivatives of neuraminic acids) constitute the major biochemical component of the mucoproteins present in the cervix and vagina (Carlborg, 1966; Coppola \& Ball, 1966; Vickery \& Bennett, 1968). Changes in sialic acid levels in the uterus (Coppola \& Ball, 1966), cervix and vagina (Carlborg \& Gemzell, 1969; Carlborg, 1969a, b, c) are dependent on ovarian hormones in rats, mice and women. However, clomiphene, a synthetic analogue of chlorotrianisene (TACE) inhibits the oestradiol-17 $\beta$-induced increase in uterine sialic acid in rats during delayed implantation (Rajalakshmi, Prasad \& Mohla, 1969).

Clomiphene, MRL-41, 1- $p$ ( $\beta$-diethylaminoethoxyphenyl) 1-2 diphenyl-2chloroethylene, is a mixture of the cis- and trans-isomers in 1:1 ratio; the cisand trans-isomers are similar to clomiphene in inhibiting the uptake of labelled oestrogen by the uterus (Wyss, Karsznia, Heinrichs \& Herrmann, 1968; 
Korenman, 1970). The two isomers of clomiphene differ, however, in the degree of their oestrogenicity, the trans- being more oestrogenic than the cisisomer (Dipietro, Sanders \& Goss, 1969; Sankaran \& Prasad, 1971). The present study examines the comparative oestrogenicity of the two isomers of clomiphene and also the comparative sensitivity of the uterus, cervix and vagina to antioestrogens, using sialic acid as an oestrogen-sensitive parameter.

\section{MATERIALS AND METHODS}

Colony-bred, adult, virgin, female rats derived from the Holtzman strain and ranging in weight from 180 to $220 \mathrm{~g}$ were used. They were housed in airconditioned rooms $\left(25 \pm 1^{\circ} \mathrm{C}\right)$ and fed a balanced diet. Tap water was freely available for drinking. Females in pro-oestrus were caged with males of proved fertility and vaginal smears were checked for the presence of spermatozoa the following morning. The day on which spermatozoa were found in the vagina was taken as Day 1 of pregnancy.

Delayed implantation was induced by the method of Cochrane \& Meyer (1957). Mated females were bilaterally ovariectomized on Day 3 of pregnancy; on the day of ovariectomy and thereafter till the termination of the experiment, each rat was given a subcutaneous injection of $4 \mathrm{mg}$ progesterone/day in $0.25 \mathrm{ml}$ olive oil. Surgical procedures were carried out under light ether anaesthesia, in semi-sterile conditions. Additional treatments were begun on Day 9 post coitum (p.c.) according to one of two schedules, described under Exp. 1 or Exp. 2.

Experiment 1: effect of different doses of the cis- or trans-isomer of clomiphene citrate

Forty-eight rats with experimentally induced delayed implantation were allocated to eight groups of six animals each. The rats in one group were killed on Day 9 p.c. and served as controls. Those in another group received a subcutaneous injection of $1 \mu \mathrm{g}$ oestradiol-17 $\beta$ in olive oil/rat on Day 9 p.c. and were killed $18 \mathrm{hr}$ after the administration of oestradiol. The rats in the other six groups received a subcutaneous injection of 150,300 or $1800 \mu \mathrm{g}$ of the cis- or trans-isomer of clomiphene citrate in oil $/ \mathrm{kg}$ body weight and were killed $18 \mathrm{hr}$ after the administration of the drug.

Experiment 2: time-sequence study of the effect of administration of cis- or transclomiphene or oestradiol-17 $\beta$

Sixty rats with delayed implantation were separated into ten groups of six rats each. A time-sequence study of the action of oestradiol-17 $\beta$, cis- or transclomiphene was made by killing the animals 6,18 or $48 \mathrm{hr}$ after a single subcutaneous injection of the compounds $(150 \mu \mathrm{g}$ cis- or trans-isomer $/ \mathrm{kg}$ body weight and $1 \mu \mathrm{g}$ oestradiol-17 $\beta /$ rat) on Day 9 p.c.

At autopsy, the uterus, cervix and vagina were quickly removed, cleared of fat and weighed to the nearest milligram on a precision torsion balance. The tissues were homogenized in cold $0 \cdot 1 \mathrm{~N}$-sulphuric acid and the homogenates were hydrolysed at $80^{\circ} \mathrm{C}$ for $1 \mathrm{hr}$. Sialic acid was estimated in the supernatants according to the method described by Warren (1959). In order to check the 
validity of the determination of sialic acid in the presence of deoxypentose, a large number of standard determinations was made of known amounts of $\mathcal{N}$-acetylneuraminic acid (NANA) in the presence of varying amounts of the deoxypentose. The recovery of NANA under these conditions was similar to that of the standard used. Moreover, with each analysis of the sialic acid in the tissue, a scan of the standard sialic acid and deoxypentose, and of equimolar concentrations of these two compounds and of the tissue extract was recorded on a recording $\mathrm{DB}$ spectrophotometer. This was done in order to check the authenticity of the components estimated in the standards and in the tissue samples. The data were analysed statistically using Student's $t$ test.

\section{RESULTS}

\section{Uterine sialic acid}

Experiment 1. Changes in uterine sialic acid following the administration of cis- or trans-clomiphene or oestradiol-17 $\beta$ are shown in Text-figs 1 and 2.

Administration of $150 \mu \mathrm{g} / \mathrm{kg}$ of either the cis- or the trans-isomer of clomiphene or of oestradiol-17 $\beta(1 \mu \mathrm{g} / \mathrm{rat})$ caused a significant increase $(P<0.001)$ in the sialic acid content of the uterus $18 \mathrm{hr}$ after the administration of the respective compounds (Text-fig. la). There was a significant increase $(P<0.001)$ in uterine sialic acid with an increase in the dose of the compound to $300 \mu \mathrm{g} / \mathrm{kg}$; however, a further increase in the dose to $1800 \mu \mathrm{g} / \mathrm{kg}$ of either of the two isomers resulted in a significant decrease $(P<0.001)$ in the uterine sialic acid.

Experiment 2. Administration of $150 \mu \mathrm{g}$ cis-clomiphene $/ \mathrm{kg}$ body weight on Day 9 p.c. caused a significant increase $(P<0.001)$ in uterine sialic acid within $6 \mathrm{hr} ; 18 \mathrm{hr}$ after the administration of the compound, however, there was a significant decrease $(P<0.001)$ in uterine sialic acid, the level reaching a plateau which persisted up to $48 \mathrm{hr}$. Trans-clomiphene caused a significant increase $(P<0.01)$ in uterine sialic acid within $6 \mathrm{hr}$, reached a peak at $18 \mathrm{hr}$, and then reached a plateau at this level which persisted up to $48 \mathrm{hr}$. Oestradiol$17 \beta$ increased uterine sialic acid within $6 \mathrm{hr}(P<0.001)$. This was followed by a significant decrease $(P<0.001)$ by $18 \mathrm{hr}$, the level reaching a plateau which persisted up to $48 \mathrm{hr}$.

\section{Cervical sialic acid}

Experiment 1. Changes in sialic acid levels in the cervix following different treatments are shown in Text-figs 1 and 3. Trans-clomiphene $(150 \mu \mathrm{g} / \mathrm{kg}$ body weight) or $1 \mu \mathrm{g}$ oestradiol-17 $\beta /$ rat increased cervical sialic acid significantly $(P<0.001)$ whereas administration of $150 \mu \mathrm{g}$ cis-clomiphene $/ \mathrm{kg}$ increased the cervical sialic acid only slightly $(P<0.05)$ (Text-fig. $1 \mathrm{~b})$. There were significant increases $(P<0.001)$ in sialic acid levels in the cervix with increase in the dose of the compounds up to $300 \mu \mathrm{g} / \mathrm{kg}$ but the levels decreased significantly following administration of $1800 \mu \mathrm{g}$ of the compounds $/ \mathrm{kg}$ (trans-clomiphene, $P<0.01$ and cis-clomiphene, $P<0.001)$.

Experiment 2. Administration of $150 \mu \mathrm{g}$ of either cis- or trans-clomiphene $/ \mathrm{kg}$ body weight or oestradiol-17 $\beta(1 \mu \mathrm{g} / \mathrm{rat})$ caused a significant increase $(P<0.001)$ in sialic acid in the cervix within $6 \mathrm{hr}$. There was a significant reduction 

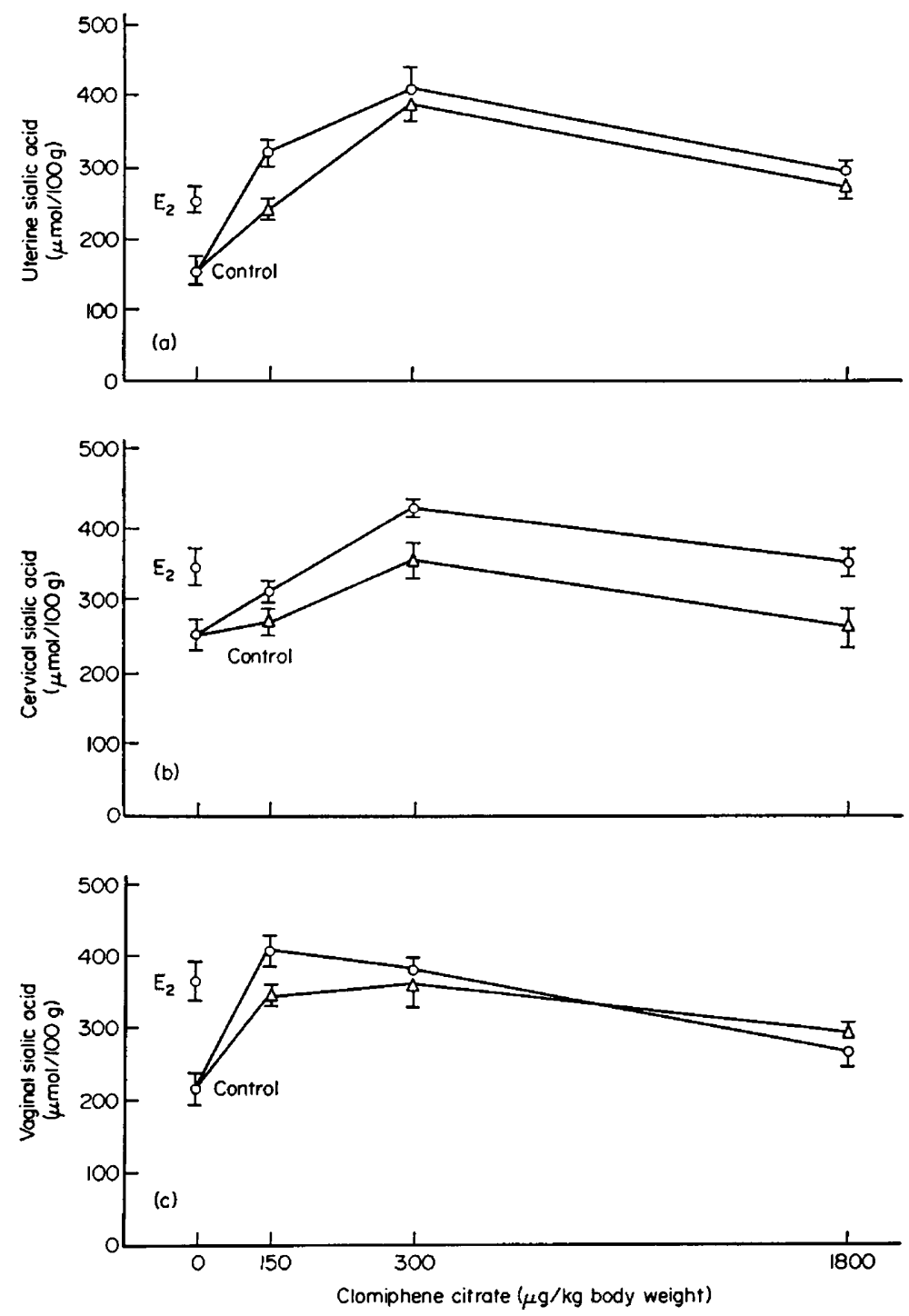

TEXT-FIG. 1. The effects of $c$ is $(\Delta)$ or trans $(0)$ clomiphene on sialic acid in the uterus (a), cervix (b) and vagina (c) of rats during delayed implantation. A description of treatments is given in the Materials and Methods section. $\mathrm{E}_{2}=$ oestradiol-17 $\beta$ ( $1 \mu \mathrm{g} /$ animal). Vertical bars represent \pm S.E.

$(P<0.02)$ in the cervical sialic acid 18 or $48 \mathrm{hr}$ after the treatment with transclomiphene (Text-fig. 3) which was still significantly higher than those of the corresponding oestradiol- or cis-clomiphene-treated rats.

Cervical sialic acid decreased to significantly low levels $(P<0.01) 48 \mathrm{hr}$ after administration of oestradiol, though the levels reached were still significantly higher $(P<0.01)$ than those of control rats. In rats treated with cis-clomiphene, there was a similar reduction in cervical sialic acid $(P<0.001)$ within $18 \mathrm{hr}$ followed by a return to control levels within $48 \mathrm{hr}$. 


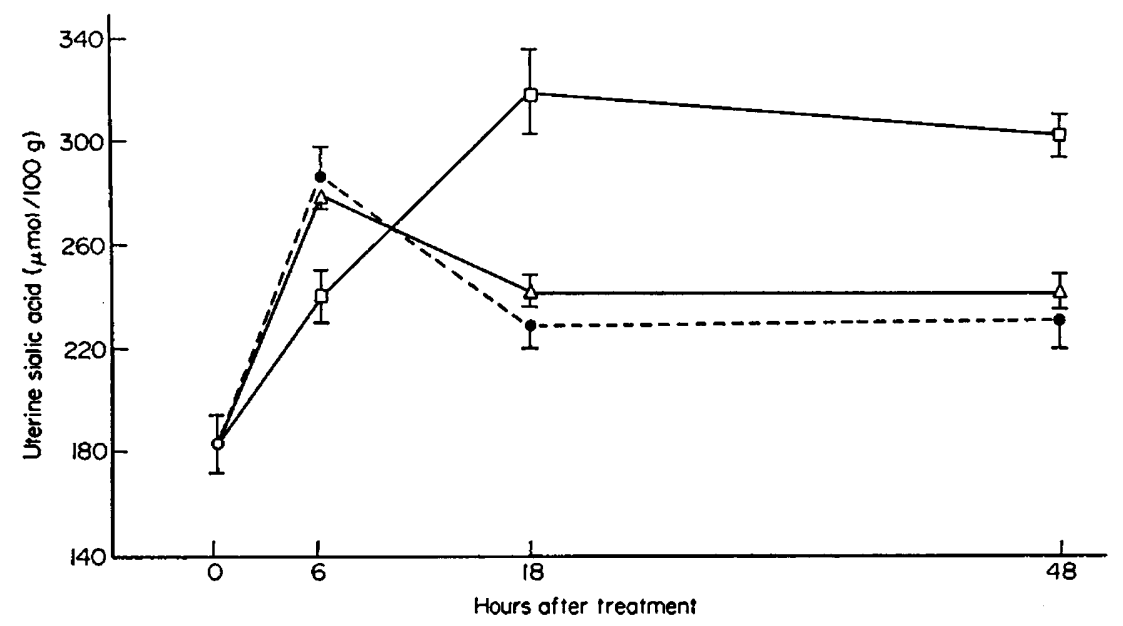

Text-FIG. 2. The time sequence of action of cis ( ) or trans $(\square)$ clomiphene or oestradiol$17 \beta(\Delta)$ on uterine sialic acid in rats. $O$, Control (progesterone).

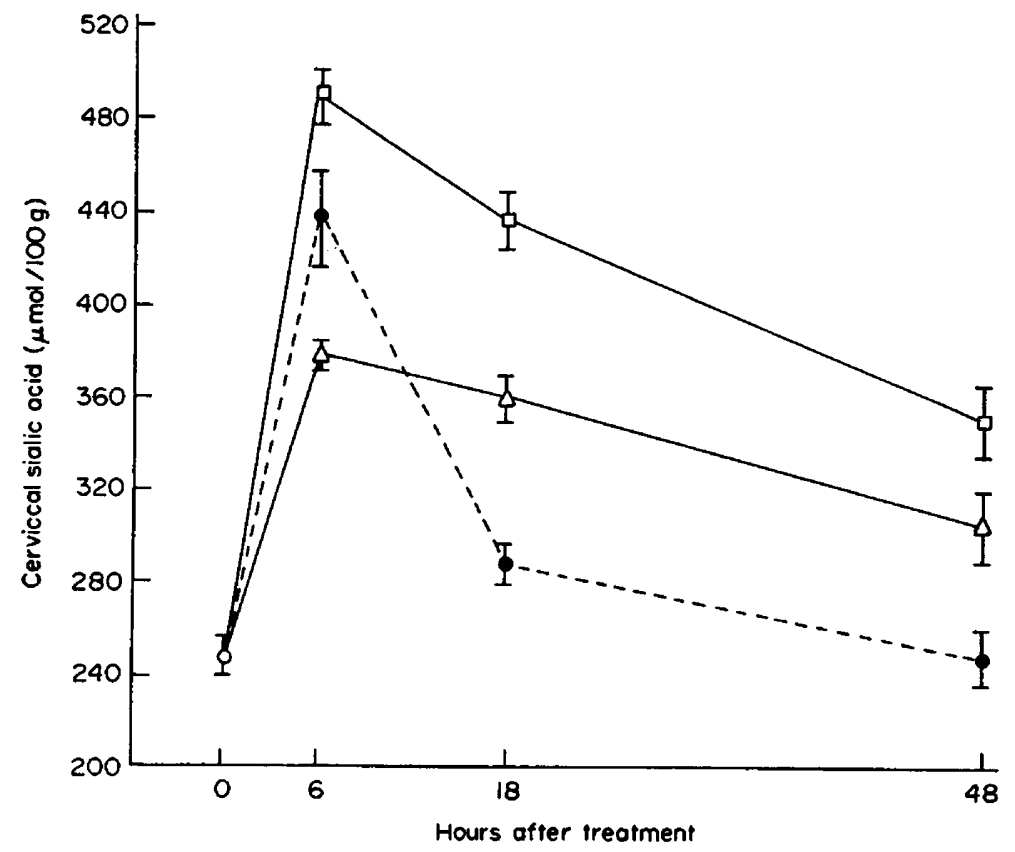

TExT-FIG. 3. The time sequence of action of cis (๑) or trans ( $\square$ ) clomiphene or oestradiol$17 \beta(\Delta)$ on cervical sialic acid in rats. $O$, Control (progesterone).

\section{Vaginal sialic acid}

Experiment 1. Changes in the vaginal sialic acid following the administration of cis- or trans-clomiphene citrate or oestradiol are shown in Text-figs 1 and 4. Administration of $150 \mu \mathrm{g}$ of either cis- or trans-clomiphene $/ \mathrm{kg}$ body weight, or of $1 \mu \mathrm{g}$ oestradiol/rat, caused a significant increase $(P<0.001)$ in vaginal sialic 
acid within $18 \mathrm{hr}$. However, an increase in the dose of either of the two isomers of clomiphene to $300 \mu \mathrm{g} / \mathrm{kg}$ did not cause any statistically significant change in vaginal sialic acid when compared with sialic acid levels attained with 150 $\mu \mathrm{g} / \mathrm{kg}$ of either of the two isomers of clomiphene $(P>0.05)$. There was a significant decrease in vaginal sialic acid following administration of $1800 \mu \mathrm{g}$ of either cis- $(P<0.01)$ or trans-clomiphene $(P<0.001 / \mathrm{kg}$, though these values were still significantly higher $(P<0.001)$ than those of control rats (Text-fig. 1c).

Experiment 2. Administration of $150 \mu \mathrm{g}$ trans-clomiphene/kg body weight caused a significant increase $(P<0.001)$ in vaginal sialic acid within $6 \mathrm{hr}$; this

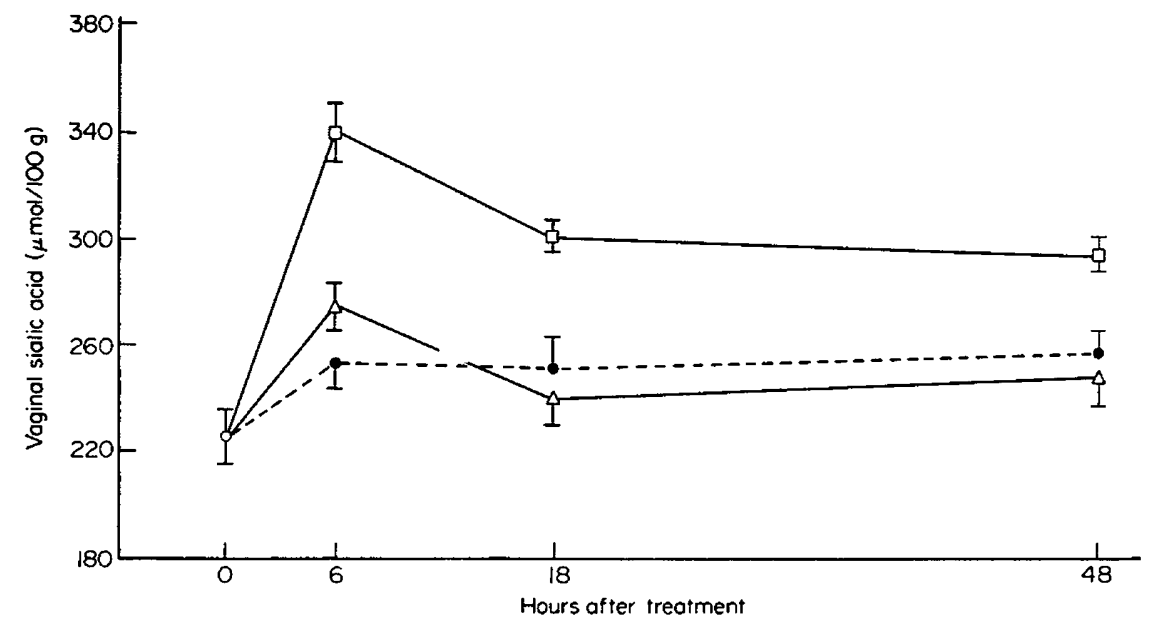

TEXT-Fig. 4. The time sequence of action of cis- (๑) or trans- ( $\square$ ) clomiphene or oestradiol$17 \beta(\Delta)$ on vaginal sialic acid in rats. $O$, Control (progesterone).

was followed by a significant decrease $(P<0.01)$ in vaginal sialic acid by $18 \mathrm{hr}$ which remained at the low level up to $48 \mathrm{hr}$ (Text-fig. 4). Cis-clomiphene $(150 \mu \mathrm{g} / \mathrm{kg})$, on the other hand, caused an increase $(P<0.05)$ in vaginal sialic acid within $6 \mathrm{hr}$ which reached a plateau at $18 \mathrm{hr}$ and persisted up to $48 \mathrm{hr}$.

Administration of $1 \mu \mathrm{g}$ oestradiol-17 $\beta /$ rat caused a significant increase $(P<0.01)$ in vaginal sialic acid within $6 \mathrm{hr}$; the level decreased significantly $(P<0.02)$ within $18 \mathrm{hr}$ and then remained at the same level $(P>0.05)$ up to $48 \mathrm{hr}$.

\section{DISGUSSION}

The effects of the cis- and trans-isomers of clomiphene citrate on the uterus, cervix and vagina in relation to concentration of sialic acid can be considered with reference to changes in sialic acid levels with varying doses of the compounds and a time-sequence response to a small dose of the compound.

The cis- as well as the trans-isomer of clomiphene citrate $(150 \mu \mathrm{g} / \mathrm{kg})$ elicited a similar response in the uterus, cervix and vagina $18 \mathrm{hr}$ after administration of the compounds (Text-fig. la, b, c), though the response of the organs to higher doses of the compounds was different. In the uterus and cervix, there 
was an increase in sialic acid with increase in the dose of the compound, whereas vaginal sialic acid decreased steadily with increases in the dose of the isomers to 300 and $1800 \mu \mathrm{g} / \mathrm{kg}$. The comparative oestrogenicity of the two isomers in increasing sialic acid in the uterus, cervix and vagina was evident with a small dose $(150 \mu \mathrm{g} / \mathrm{kg})$ in the uterus and vagina, whereas in the cervix there was a clear difference in the response to different doses of cis-or trans-clomiphene. The decrease in vaginal sialic acid in relation to increased doses of antioestrogens has been shown in the mouse (Carlborg, 1969a, b, c).

Administration of trans- or cis-clomiphene or oestradiol-17 $\beta$ elicited a sharp increase in uterine sialic acid within $6 \mathrm{hr}$ of the administration of the compounds. It has also been shown by Rajalakshmi et al. (1969) that clomiphene induced a sharp increase in uterine sialic acid within $6 \mathrm{hr}$ in rats during delayed implantation which was less than that caused by oestradiol at the same time interval. Differences in the time sequence of the action of the isomers of clomiphene on uterine sialic acid (Text-fig. 2) show that cis-clomiphene acts much earlier than trans-clomiphene in enhancing the sialic acid level. A similar time lag in the action of trans-clomiphene was also demonstrable with respect to its action on uterine glycogen and liver glycogen (Sankaran \& Prasad, 1971). Although the oestrogenicity of trans-clomiphene is manifested slowly in comparison with that of the cis-isomer, it lasts for a longer period of time (Text-figs 2, 3 and 4).

The increase in vaginal sialic acid following treatment with trans-clomiphene was significantly more than that following treatment with oestradiol or cisclomiphene at all time intervals studied.

When the sialic acid responses in the uterus, cervix and vagina are compared, it appears that trans-clomiphene is more oestrogenic than cis-clomiphene in rats.

In the present study, the uterus, cervix and vagina clearly responded differently to the various treatments. Such variations in the degree of sensitivity of different parts of the female genital tract to oestrogens have been reported earlier; Lerner, Harris, Hilf, Bianchi \& Raskin (1966) studied a variety of biochemical parameters sensitive to ovarian hormones in the oviduct and uterus of ovariectomized rats following the administration of ovarian hormones and hormonal antagonists. They found differences in the responses of the biochemical parameters studied in the oviduct and uterus with reference to the time as well as to the type of response. Datta, Karkun \& Kar (1968) reported differences in the response of biochemical parameters in the rat cervix and uterus during the oestrous cycle. Although such differences in response between different parts of the female genital tract to ovarian hormones have been reported by other workers also (Gregoire, Ramsey \& Adams, 1967; Sankaran, 1971), it is difficult to offer a reasonable explanation for these differences. In an extensive review of the history of the development of the female reproductive tract in many common laboratory animals and man, Zuckerman (1940) related the differences in the cellular responses of the various parts of the female genital tract following administration of oestrogens to differences in their embryological origin. The Fallopian tube, the uterus and the cervix uteri differentiate from the Müllerian duct. The vagina, on the other hand, is differentiated from the urogenital sinus which is endodermal in origin, while the vulval and perigenital areas are ectodermal in origin (Davies, 1967). It is interesting to note that 
differences in the cellular responses to oestrogen administration in the female genital tract are also reflected in the biochemical responses, as shown by the changes in various parameters discussed above. Whether these differences in biochemical responses reflect differing modes of action of oestrogens and antioestrogens or whether they are related to the embryology of various parts of the female reproductive tract or to the function of sialic acid in the uterus, cervix and vagina remains to be elucidated.

\section{AGKNOWLEDGMENTS}

This investigation was supported by a grant from the Ford Foundation, the Ministry of Health and Family Planning, Government of India and the Indian Council of Medical Research. The generous gift of isomers of clomiphene by Dr D. E. Holtkamp, Wm. S. Merrel \& Co., Cincinnati, U.S.A., is acknowledged with thanks.

\section{REFERENCES}

CARLborg, L. G. (1966) Quantitative determination of sialic acids in the mouse vagina. Endocrinology, $78,1093$.

CARlborg, L. (1969a) Action of diethylstilboestrol on mouse vaginal sialic acids (I). Acta endocr., Copenh. 62, 657.

CARlborg, L. (1969b) Comparative action of various oestrogenic compounds on mouse vaginal sialic acids (II). Acta endocr., Copenh. 62, 663.

Garlborg, L. (1969c) Hormone dependency of the mouse vaginal sialic acid content and the sialic acid content of human cervical mucus under physiological and experimental conditions. Acta Universitatis upsaliensis, $\mathbf{7 4}, 1$.

Garlborg, L. \& Gemzeld, G. (1969) Sialic acid content and sperm receptivity of cervical mucus in relation to oestrogen excretion following administration of FSH. Acta endocr., Copenh. 62, 711.

Cochrane, R. L. \& Meyer, R. K. (1957) Delayed nidation in the rat induced by progesterone. Proc. Soc. exp. Biol. Med. 96, 155.

Coppola, J. A. \& Ball, J. L. (1966) Uterine sialic acid in relation to ovarian steroids. Steroids, 8, 345.

DatTA, I. G., Karkun, J. N. \& Kar, A. B. (1968) Studies on physiology and biochemistry of the cervix: changes in the cervix of rats during estrus cycle. Acta biol. med. germ. $20,147$.

Davies, J. (1967) Comparative embryology. In: Cellular Biology of the Uterus, p. 13. Ed. Ralph M. Wynn. North Holland Publishing Company, Amsterdam.

Dipietro, D. L., Sanders, F. J. \& Goss, D. A. (1969) Effect of cis and trans isomers of clomiphene citrate on uterine hexokinase activity. Endocrinology, 84, 1404.

Gregorre, A. T., RAmsey, H. \& ADAMs, A. (1967) The effect of various doses of oestradiol 17- $\beta$ on glycogen deposition in the rat uterus, cervix and vagina. F. Reprod. Fert. 14, 231.

Korenman, S. G. (1970) Relation between estrogen inhibitory activity and binding to cytosol of rabbit and human uterus. Endocrinology, 87, 1119.

Lerner, L. J., Harris, D. N., Hilf, R., Bianchi, A. \& Raskin, B. K. (1966) Responses of the rat oviduct and uterus to sex steroids as influenced by time and antagonists. In: Proc. 2nd Int. Congr. Horm. Steroids, Milan. Eds. E. B. Romanoff \& L. Martini. Excerpta med. Int. Congr. Series, 111, p. 58.

Rajalakshmi, M., Prasad, M. R. N. \& Mohla, S. (1969) Effect of estrogen and clomiphene on uterine sialic acid in the rat during delayed implantation. Steroids, 14, 47.

Sankaran, M. S. (1971) Oestrogen-antioestrogen interaction in rats during delayed implantation. Ph.D. thesis, University of Delhi.

Sankaran, M. S. \& Prasad, M. R. N. (1971) Comparative estrogenicity of cis and trans isomers of clomiphene citrate in rats during delayed implantation. Steroids, 18, 511 .

Vickery, B. H. \& BenNeTr, J. P. (1968) The cervix and its secretion in mammals. Physiol. Rev. 48, 135.

WARren, L. (1959) The thiobarbituric acid assay of sialic acids. F. biol. Chem. 234, 1971.

Wyss, R. H., Karszinia, R., Heinrichs, W. L. \& Herrmann, W. L. (1968) Inhibition of uterine receptor binding of estradiol by antiestrogens (clomiphene and CL-868). J. clin. Endocr. Metab. 28,1824 .

Zuckerman, S. (1940) The histogenesis of tissues sensitive to estrogens. Biol. Rev. 15, 231. 